\title{
Transrectal High-Intensity Focused Ultrasound for the Treatment of Localized Prostate Cancer: Current Role*
}

\author{
Christian Chaussy ${ }^{1,2 \#}$, Derya Tilki ${ }^{1,3}$, Stefan Thüroff ${ }^{1,4}$ \\ ${ }^{1}$ Harlachinger Krebshilfe e.V., Munich, Germany; ${ }^{2}$ Department of Urology, University of Regensburg, Regensburg, Germany; \\ ${ }^{3}$ Department of Urology, Ludwig-Maximilians-University, Munich, Germany; ${ }^{4}$ Department of Urology, Klinikum Harlaching, Mu- \\ nich, Germany. \\ Email: "cgchaussy@googlemail.com
}

Received February $26^{\text {th }}, 2013$; revised March 27 $7^{\text {th }}, 2013$; accepted April $3^{\text {rd }}, 2013$

Copyright (C) 2013 Christian G. Chaussy et al. This is an open access article distributed under the Creative Commons Attribution License, which permits unrestricted use, distribution, and reproduction in any medium, provided the original work is properly cited.

\begin{abstract}
Over the past 25 years, the average life expectancy for men has increased by 4 years, and the age of prostate cancer detection has decreased an average of 10 years with diagnosis increasingly made at early-stage disease where curative therapy is possible. These changing trends in the age and extent of malignancy at diagnosis have revealed limitations in conventional curative therapies for prostate cancer, including a significant risk of aggressive cancer recurrence, and the risk of long-term genitourinary morbidity and its detrimental impact on patient quality of life (QOL). Greater awareness of the shortcomings in radical prostatectomy, external radiotherapy and brachytherapy have prompted the search for alternative curative therapies that offer comparable rates of cancer control and less treatment-related morbidity to better preserve QOL. High intensity focused ultrasound (HIFU) possesses characteristics that make it an attractive curative therapy option. HIFU is a non-invasive approach that uses precisely-delivered ultrasound energy to achieve tumor cell necrosis without radiation or surgical excision. In current urological oncology, HIFU is used clinically in the treatment of prostate cancer, and is under experimental investigation for therapeutic use in renal and breast malignancies. Clinical research on HIFU therapy for localized prostate cancer began in the 1990s, and there have now been approximately 30,000 prostate cancer patients treated with HIFU, predominantly with the Ablatherm (EDAP TMS, Lyon, France) device. Transurethral resection of the prostate (TURP) has been combined with HIFU since 2000 to reduce prostate size, facilitate tissue destruction, and to minimize side effects. Advances in imaging technologies are expected to further improve the already superior efficacy and morbidity outcomes, and ongoing investigation of HIFU as a focal therapy and in salvage and palliative indications are serving to expand the role of HIFU as a highly versatile non-invasive therapy for prostate cancer.
\end{abstract}

Keywords: High Intensity Focused Ultrasound (HIFU); PCa Therapy Non-Invasive; Focal Therapy Hormone Resistant $\mathrm{PCa}$

\section{The Clinical History of HIFU}

Although knowledge that tissue destruction could be achieved with high-intensity focused ultrasound (HIFU) has been around since the 1930 s, efforts to clinically implement this technology were delayed due to the absence of imaging technology to monitor the procedure [1]. Basic research in the urological application of HIFU began in the 1980s, primarily in France and the USA, when computer technology became sufficient to facilitate the control and management of this fascinating energy

\footnotetext{
*The authors hereby confirm that they have nothing to disclose.

${ }^{\#}$ Corresponding author.
}

source. The first clinical prototypes for use in urology emerged during this period.

Clinical trials of HIFU began in the early 1990s in Europe, Japan, and the USA, with initial evaluation as a therapy for benign prostatic hyperplasia. HIFU demonstrated safety and efficacy through the precise destruction of local tissue. Also the induction of a significant shrinkage process within the treated organ and resultant therapy-related side effects was observed. Thus, HIFU was found to possess the effective attribute needed for cancer treatment of tissue destruction, but it was not effective in infravesical deobstruction, where obstruction was increased from shrinkage and necrotic tissue. Early clinical trials of HIFU therapy for prostate cancer during 
the mid-late 1990s found a relationship between the coagulated prostate volume with HIFU and obstruction, and analysis of prospective studies also found a high rate of urinary tract infections in this necrotic tissue. As the result of the association between HIFU and obstruction, and consistent with the whole-gland concept of therapy, HIFU has been routinely combined with an adjuvant TURP since $2000[2,3]$ to debulk the tumor mass and radically resect the middle lobes, calcifications, abscesses, and bladder neck [4].

The current use of HIFU involves computers, special software, transrectal ultrasound devices and MRI to allow real-time control and monitoring during the treatment session. HIFU therapy has been extended to different surgical indications such as use as an extracorporeal method that allows non-invasive coagulative destruction without an open surgical procedure. The validation and international acceptance of transrectal HIFU treatment of prostate cancer has been increasing as the result of the growing clinical experience and published research on HIFU. Although 5-year efficacy results are available $[5,6]$, long-term cancer control data from 10-year patient follow-up await to be published.

\section{HIFU Mechanisms and Technology}

\subsection{Mechanism of Action of HIFU}

The first reported use of HIFU in local tissue destruction was made in 1944 by Lynn and Putman [7]. The use of high-energy parabolic-focused ultrasound results in the mechanical alteration and changes in the biological structure of targeted cells [Figure 1] [1]. During the application of focused ultrasound, two different physical mechanisms account for its treatment effect: thermal and mechanical.

\subsubsection{Thermal}

The ultrasound energy produced by HIFU is absorbed by the targeted tissue and converted into heat. The extent of temperature increase in the tissue depends on the absorption coefficient of the tissue, and the size, shape and temperature sensitivity of the heated area [1]. Biological changes caused by the heating depend on the temperature level and duration of exposure. A "thermal dose", which exceeds a certain threshold, causes tissue coagulation and leads to irreversible tissue damage through coagulative necrosis [8]. The focused ultrasound waves of HIFU are capable of inducing sharp increases in temperature (around $70^{\circ} \mathrm{C}$ to $100^{\circ} \mathrm{C}$ ) in a few seconds. During the clinical use of HIFU, the tissue-sensitive adjacent structures such as the rectum, external sphincter, and the neurovascular bundles are spared from destruction due to the steep temperature gradient between the focal tissue and surrounding region $[8,9]$.

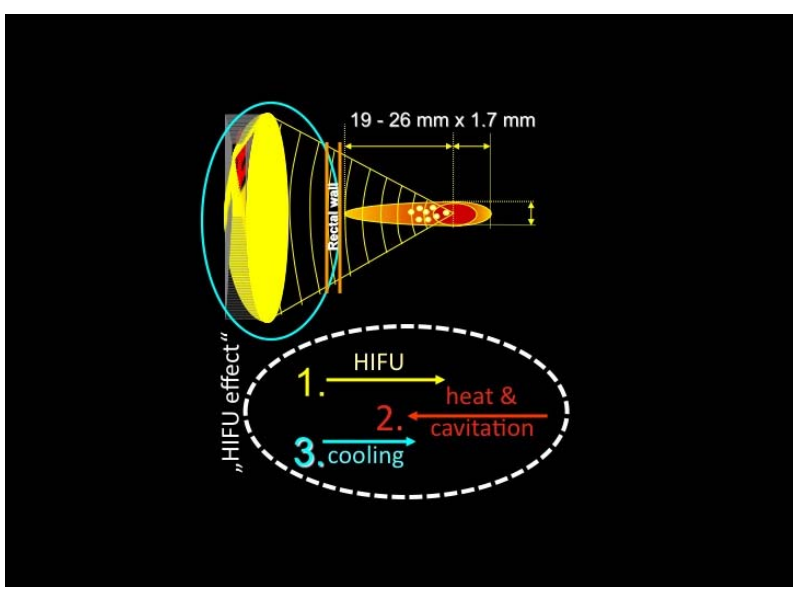

Figure 1. physical principle of focused energy application.

\subsubsection{Mechanical}

The mechanical effects of HIFU are induced by the effects of negative pressure of the ultrasound wave on the targeted tissue [1]. The negative pressure causes bubbles to form inside the targeted cells which increase in size to the point at which resonance is achieved. High pressure of 20,000 - 30,000 bars develops when these bubbles suddenly collapse, causing damage to nearby cells and the formation of a cavitation effect within the tissue which damages cell membranes [10]. The primary single lesions are small $(1.7 \times 19-26 \mathrm{~mm})$ and produce reproducible volumes of sharply demarcated ablation [9]. The small volume of tissue destroyed by a single burst of ultrasound is termed the elementary or primary lesion. To create larger lesions, several elementary lesions are made side by side, by adding multiple lesion targets to the algorithm [Figures 2(a) and (b)] and either mechanically moving the transducer or by electronically positioning the focal point if a phased array is available $[8,11-15]$.

\subsection{Experimental Identification of Clinical Parameters}

In vitro, in vivo, and computer simulation studies were conducted to identify and refine the ultrasound parameters required for the clinical treatment of prostatic disease. The destruction of tumors with HIFU in these studies provided the evidence that cancerous tissues can be destroyed by HIFU without inducing metastases [16], and that prostatic tissue can effectively be targeted through transrectal delivery of HIFU $[17,18]$.

\subsection{Essential Clinical Parameters of HIFU}

High-intensity focused ultrasound can be delivered as a pulsed or a continuous beam [19]. The latter process includes solar waves, microwaves and radar technology, whereas pulsed HIFU is applied as medical HIFU and extracorporeal shockwave lithotripsy. The high-frequency 


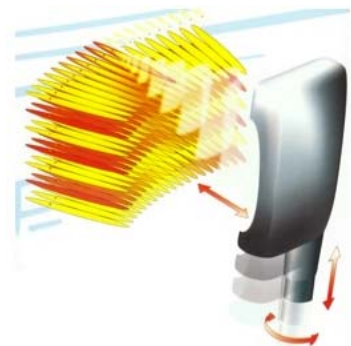

(a)

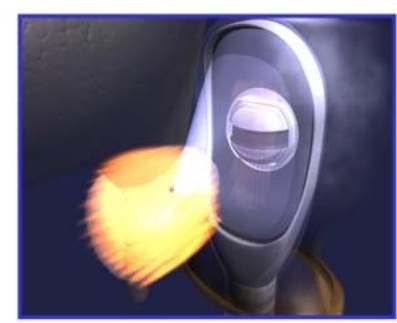

(b)

Figure 2. (a) Multiple lesion application mode and; (b) Volume coagulation (transducer movement algorithm).

vibration $(0.5-10 \mathrm{MHz})$ of a piezoelectric or piezoceramic transducer generates ultrasound waves, which are focused into a focal point by a concave or parabolic arrangement [10].

Essential parameters for the medical use of HIFU include: 1) the ultrasound frequency (MHz); 2) the acoustic intensity (Watts); 3) the duration of application (shottime); 4) the intervals of the pulses (delay-time); 5) the lateral distance between elementary lesions; 6) the longitudinal displacement of the energy source when applying multiple lesions; and 7) the penetration depth (focal point) dependent on the applicator design [1].

These multiple technical parameters are essential in the assembly of a HIFU system with a dedicated application for specific tissue. Complex technical decisions are involved in HIFU operation, and include the selection and design of the piezoelectric energy applicator, the parameters of ultrasound treatment $(\mathrm{MHz}$, Watts), the application algorithm (impulse-delay relation), the imaging system, the intraoperative target and safety features, target localization during treatment with TRUS or MRI, and controls [1].

The ultrasonic energy transducer is characterized mainly by its operating frequency, and geometric and physical dimensions. Piezoelectric systems can be operated with sufficient energy density, reproducibility and long-term stability in accordance with the requirements of the therapy, which allow the production of geometric shapes for adaptation to changing anatomical needs [13]. Current standard urological applications use HIFU transducers with a fixed but adjustable focal point to be moved mechanically to treat a larger tissue volume [Figure 3] [14, $15]$.

\subsection{Commercially Available HIFU Devices for Prostate Cancer}

As of 2011, two transrectal HIFU devices were comercially available for the treatment of prostrate cancer, the Ablatherm ${ }^{\circledR}$ [EDAP TMS, Lyon, France] and the Sonablate [Misonix, Inc., Farmingdale, NY] [Figure 4]. Although neither device has received FDA approval for
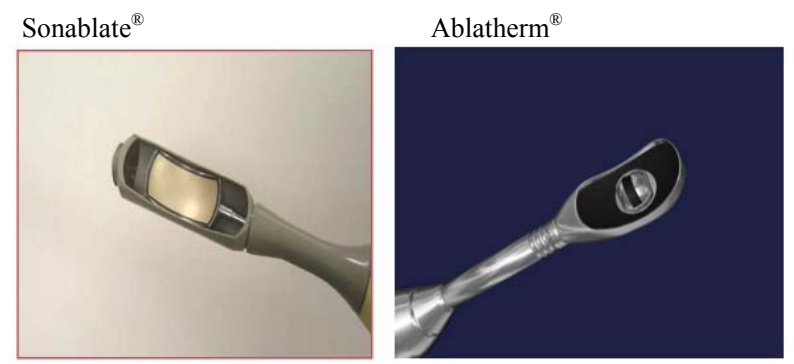

Figure 3. Different transrectal HIFU transducers for Sonablate $^{\circledR}$ and Ablatherm ${ }^{\circledR}$.
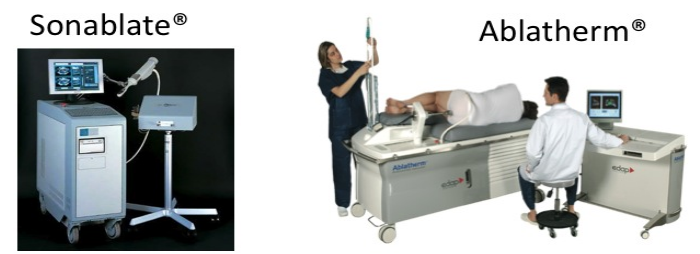

Figure 4. 2 commercially available transrectal HIFU devices: Ablatherm ${ }^{\circledR}$ and Sonablate ${ }^{\circledR}$.

marketing in the US, regulatory clearance is likely for the Ablatherm device when the results of a prospective trial become available [1]. The two devices differ on numerous dimensions, prohibiting the pooling of outcome data from both devices for analysis in aggregate. Because HIFU with Ablatherm ${ }^{\circledR}$ constitutes the vast majority of the body of research involving prostate cancer therapy with HIFU, studies involving the Ablatherm ${ }^{\circledR}$ device are the sole focus of this review.

In addition to the peer-reviewed literature and conference presentations reporting treatment outcomes with the Ablatherm device, oral communications are also of interest when considering a rapidly evolving technology such as HIFU. The Cancer Committee of the French Urology Association has produced a review of relevant communications relating to HIFU [20].

\subsubsection{Ablatherm ${ }^{\circledR}$}

The Ablatherm ${ }^{\circledR}$ machine consists of a treatment module that includes the patient's bed, the probe positioning system, the ultrasound power generator, the cooling system for preservation of the rectal wall, and the ultrasound scanner used during the treatment localization phase. There is also a treatment and imaging endorectal probe that incorporates both a biplanar imaging probe working at $7.5 \mathrm{MHz}$ and a treatment transducer focused at a maximum of $45 \mathrm{~mm}$ working at $3 \mathrm{MHz}$ [21].

Numerous safety features have been incorporated, including a safety ring that stabilizes the rectal wall during transducer movements, a permanent control of the distance between the therapy transducer and the rectal wall, and a patient motion detector that stops treatment if the patient moves during the firing sequence [21]. 
The treatment parameters are selected to optimize the size of the lesion while leaving the rectal wall and surrounding tissues intact [Figures 5(a) and (b)]. The size of the elementary lesion is between 19 and $24 \mathrm{~mm}$ in length and $1.7 \mathrm{~mm}$ in diameter. Because the shape of the lesion depends on gland perfusion, treatment parameters are different according to the patient's status: $5 \mathrm{~s}$ treatment pulse and $5 \mathrm{~s}$ shot interval for the first HIFU session in primary-care treatment; $4.5 \mathrm{~s}$ treatment pulse and $5 \mathrm{~s}$ shot interval for the second session in primary care; and $4 \mathrm{~s}$ treatment pulse and $7 \mathrm{~s}$ shot interval for local relapse after external-beam radiation therapy [21].

HIFU is delivered as a single-session therapy under spinal anesthesia for a duration of 2 to 3 hours. The treatment is conducted with the patient in the lateral position. The endorectal probe containing a curved piezoelectric crystal and a transrectal ultrasound (TRUS) scanner is placed in a latex balloon filled with cooling fluid and introduced into the rectum. This probe collects emitted ultrasound beams at a focal point. Following definition of the target volume boundaries by the operator, treatment is performed from the apex to the base of the prostate [Figure 6]. Usually four to eight successive target volumes are defined in order to treat the entire prostate. At the end of the HIFU session, a Foley-type urinary catheter or a suprapubic tube is positioned [21].

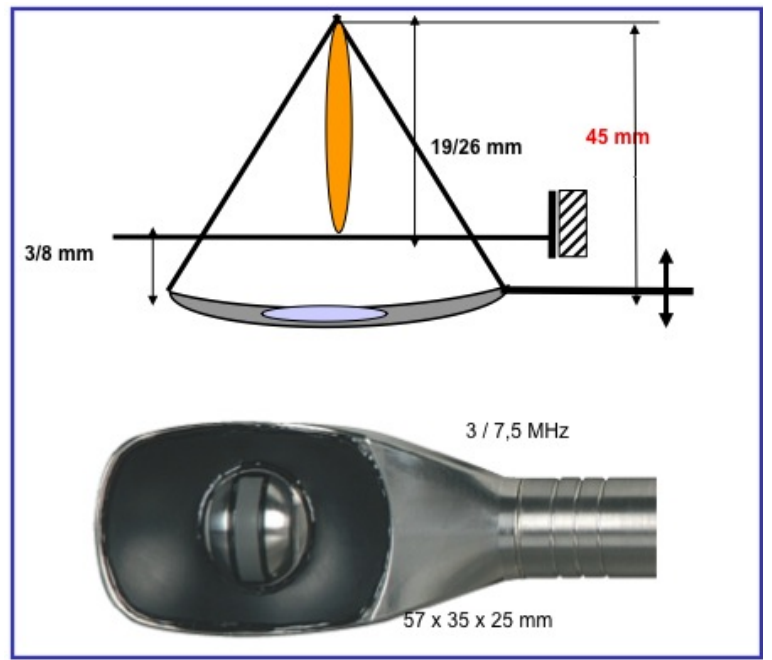

(a)

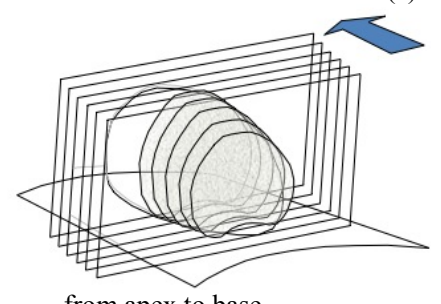

from apex to base

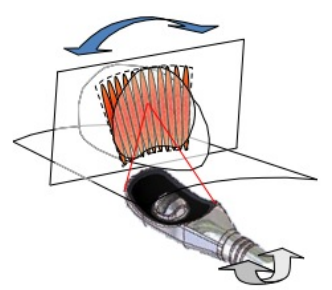

from left to right (b)

Figure 5. Focal point adjustment: (a) Penetration depth (19 - 26 mm); (b) Latero-longitudinally (1.7 mm steps).

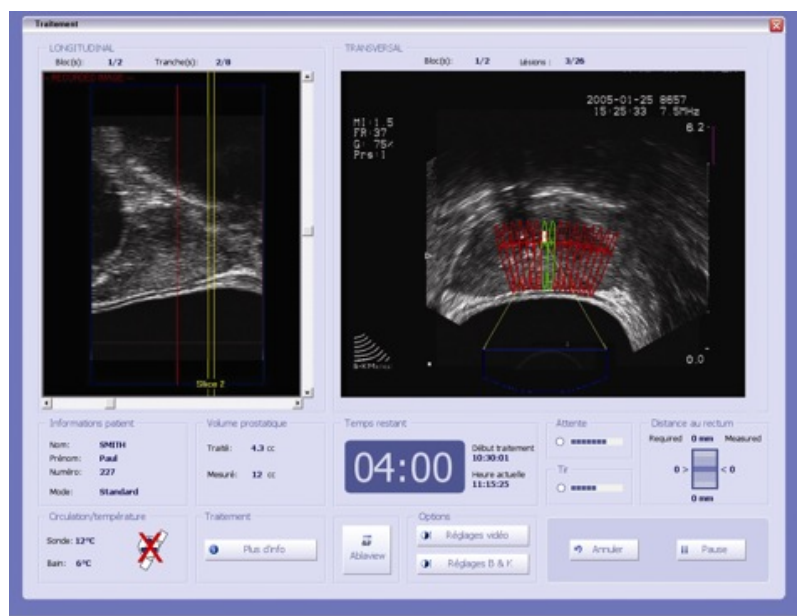

Figure 6. Intraoperative, 3-dimensional, real-time, transrectal ultrasound for visual treatment planning and control on control screen.

\subsubsection{Sonablate ${ }^{\circledR}$}

Unlike the Ablatherm ${ }^{\circledR}$ machine, the Sonablate ${ }^{\circledR}$ system has no dedicated bed. Several treatment probes are available, and are selected by the operator according to the size of the elementary lesion required: $10 \mathrm{~mm}$ in length and $2 \mathrm{~mm}$ in diameter for a single beam performing with $25 \mathrm{~mm}$ or $45 \mathrm{~mm}$ focal-length probes; and 10 $\mathrm{mm}$ in length and $3 \mathrm{~mm}$ in diameter for a split beam performing with 30,35 or $40 \mathrm{~mm}$ focal-length probes [22]. Treatment parameters may also vary depending on operator choice.

Treatment is performed with the patients in a dorsal position under general anesthesia. The probe is chosen depending on prostate size, with larger glands requiring longer focal lengths. The treatment is usually made in three consecutive coronal layers, starting from the anterior part of the prostate and progressively moving to the posterior part, with at least one probe switch during the procedure [22].

\subsection{Measurement of HIFU Effects on Prostatic Tissue}

\subsubsection{Histological Effects}

The clinical potential of HIFU in the treatment of prostate cancer was established in a clinical trial where patients received HIFU 1 to 2 weeks before receiving radical prostatectomy, followed by histologic examination of the removed prostate. HIFU was delivered to regions of the prostate where biopsies had revealed cancer, and histologic examination found a sharp demarcation between HIFU-treated and untreated areas, with complete necrosis in all specimens [23]. Fat-saturated gadolinium-enhanced MRI has demonstrated the extent of the tissue damage induced by HIFU. Treated areas appear as a non-enhancing hypointense zone surrounded by a peripheral rim 
of enhancement 3 to $8 \mathrm{~mm}$ thick. These abnormalities correspond to a nucleus of coagulation necrosis surrounded by a peripheral zone of inflammation. Treatment-induced abnormalities visible with MRI usually disappear in 3 - 5 months in a centripetal manner, and HIFU-induced tissue contraction results after about 6 months in small prostates of approximately 5cc [24].

\subsubsection{Imaging with Clinical Use}

MRI is considered the gold-standard technique used for assessing the efficacy of HIFU treatment. The extent of necrosis can be clearly visualized on gadolinium-enhanced T1-weighted images, as hyposignal zones [25]. MRI has also been used to guide HIFU treatments [25, $26]$, as it is possible to monitor the temperature changes within tissues with MRI during HIFU [25]. Magnetic resonance elastography has also been proposed as a method for assessing the effects of thermal tissue abla- tion by measuring the mechanical properties of the lesion [26]. It remains unclear whether elastographic changes are correlated with long-term tissue destruction and whether they reflect complete tissue coagulation at a cel- lular level [27]. HIFU-induced lesions are visible using standard ultrasound as hyperechoic regions; however, the real extent of primary lesion destruction cannot be defined precisely because of variations across patients in interfering effects such as HIFU reflection (prostatic capsule, calcifications, catheters); absorption (untreated or pretreated tissue); and cooling (blood vessels, intraprostatic TURP cavity liquid) [28]. Techniques to improve characterization based on ultrasound, contrast-enhanced Doppler [29], and measurement of the acoustic behavior of tissues have been proposed to more accurately determine the extent of HIFU-induced lesions [30]. During 15 years of clinical experience with HIFU treatment of prostate cancer, transrectal ultrasound has been shown to be a safe reproducible application even without "real time" temperature measurement [Figure 4]. However, a "real time" technology that compensates for the limitations in tissue visualization mentioned above would be an advantage that would help optimize tissue ablation efficacy [1].

\section{Indications for HIFU Therapy of Prostate Cancer}

The most widespread use of HIFU, and initially the only indication for its use, has been in patients with localized prostate cancer (T1-2N0M0; Gleason sum $\leq 6)$ who are not candidates for surgery because of age, general health status, a prohibiting comorbidity or a preference not to undergo a radical prostatectomy [1]. However, with the accumulation of clinical experience and expansion of research protocols these indications have broadened to include partial therapy in unilateral low-volume, low-GS tumors (T1-2aNx/0M0; PSA $\leq 20 \mathrm{ng} / \mathrm{ml}$ ); salvage therapy in recurrent prostate cancer following radical prostatectomy, radiation therapy or hormone ablation (all TNx/0M0; all GS/PSA) [31]; advanced prostate cancer as an additional neoadjuvant debulking process (T3-4Nx/ 0M0; all GS/PSA) [32]; and in hormonal resistant prostate cancer (HRPCa). In contrast to radiation therapy, HIFU can also be used in intermediate- and high-risk patients. Most studies have used HIFU with inclusion of these patient groups with reasonable outcomes [33,34], but as with the other curative therapies, high-risk patients have a lower success rate than low-risk patients. Remaining contraindications common to both HIFU devices include a missing or small rectum, and a damaged rectal wall from previous prostatic or rectal therapies [1].

The diagnosis of prostate cancer is based on the histopathological examination of biopsies in cases of suspicious PSA findings, digital rectal examination, magnetic resonance imaging, transrectal ultrasound (TRUS), or unexpected findings in resected tissue after open adenomectomy, holmium, or transurethral resection [35].

\section{Combining Transurethral Resection of the Prostate (TURP) and HIFU}

The use of TURP with HIFU became routine practice in 2000 as a means to reduce post-HIFU urethral sloughing and obstruction, and offers several other advantages over HIFU alone. The combined procedure of TURP prior to HIFU in patients with localized prostate cancer allows the instant removal of any reflecting or deviating calcifications of the transitional zone that would prevent HIFU treatment, as well as abscesses, intravesical middle lobes and large $(>40 \mathrm{ml})$ adenomas [1]. The generation of a cavity and its subsequent compression by the rectal balloon increases the accessibility of the HIFU waves to the remaining gland [Figure 7], fixes the residual prostate behind the symphysis, avoids movement artefacts, and allows the complete treatment of the peripheral zone in a single HIFU session. Also, the penetration depth of the HIFU device is $26-28 \mathrm{~mm}$, and without a TURP a larger gland size $(>30 \mathrm{ml})$ is considered a contraindication. TURP decreases the size of each prostate gland to approximately $25 \mathrm{ml}$ to eliminate size restriction with HIFU $[2,36]$.

\section{Efficacy of HIFU as Primary Therapy}

\subsection{Efficacy in Localized Disease}

Similar to efficacy studies with external beam radiotherapy, brachytherapy, and cryoablation, biochemical markers and biopsy findings have been used as indicators of long-term cancer control with HIFU. To date there is no 

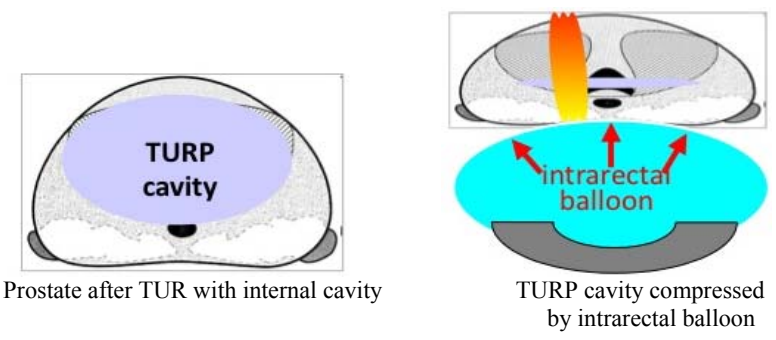

Figure 7. Compression and retropubic fixation of transurethrally resected prostate.

universal consensus on the definition of biochemical failure in patients treated with HIFU [1]. With ongoing refinements in execution and outcome measurement, the efficacy of HIFU in locally confined prostate cancer is now comparable to those of radiotherapy and radical prostatectomy, which according to the CaPSURE database are characterized by failure rates of $63 \%$ at a mean of 38 months post treatment and $30 \%$ at a mean of 34 months post treatment, respectively [37].

Early efficacy studies of HIFU defined complete response as a negative control biopsy and a PSA nadir < $4.0 \mathrm{ng} / \mathrm{ml}$. [38,39]. Stricter criteria for treatment failure were applied by Gelet et al., with failure defined as any positive biopsy or three successive elevations in PSA with a velocity of $0.75 \mathrm{ng} / \mathrm{ml} /$ year or greater [40]. The French Urological Association guidelines in 2005 stated that biopsy was required if there were three successive elevations in PSA level over a 3-month period but not if the PSA nadir was less than $1.0 \mathrm{ng} / \mathrm{ml}$ [41]. The American Society for Therapeutic Radiology and Oncology (ASTRO) definition of disease-free status based on biochemical outcome has been applied to HIFU. PSA failure was also defined as three consecutive PSA rises after a nadir, with the date of failure being the halfway point between the nadir date and the first rise or any rise great enough to provoke initiation of salvage therapy [34]. This definition was subsequently modified to the Phoenix definition of failure as the time at which PSA $>$ nadir + $2.0 \mathrm{ng} / \mathrm{ml}$ was reached. A number of HIFU studies have now applied the ASTRO or Phoenix definitions. Table 1 provides a summary of HIFU efficacy in localized prostate cancer.

HIFU efficacy has also been reported in terms of negative biopsy rate, which is likely to provide the best measure of definitive efficacy despite the associated sampling error. The lowest reported negative biopsy rate was by Gelet $e$ al. in 2001 [42], which included patients treated with prototype devices. The only other series reporting a negative biopsy rate less than $80 \%$ was Ficarra et al. [33], who included patients with high-risk prostate cancer [6]. In more recent series, negative biopsy rates have ranged from $93 \%$ - 96\% [5,43]. Re-treatment rates have also been reported in the literature but their interpretation is confounded by the former practice of using two treatment sessions with only one prostatic lobe treated in each session. This approach was common in the studies of Gelet et al. [42] and Poissonnier et al. $[6,44]$, and the only series that did not use this approach was the series involving high-risk patients reported by Ficarra et al. [33]. Unfortunately, the proportion of patients treated intentionally with two sessions versus those re-treated due to clinical failure was not reported in these studies.

Blana et al. reported HIFU treatment outcomes by utilizing a large international patient series from the @--Registry [45]. Patients in the @-Registry were stratified according to D'Amico's 2003 risk group definitions

Table 1. Robotic high-intensity focused ultrasound: efficacy summary.

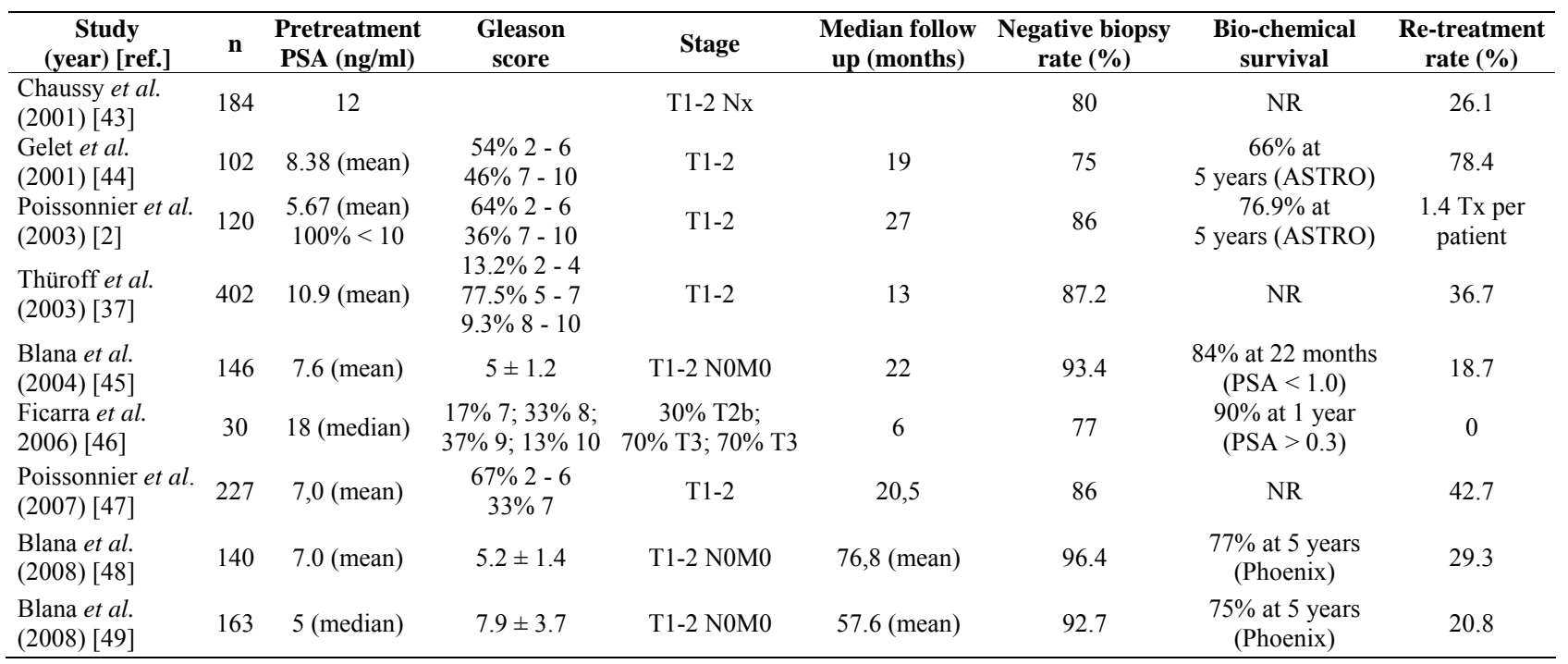

ASTRO: American Society for Therapeutic Radiology and Oncology; Nx: Lymph nodes not tested; PSA: Prostate-specific antigen; Tx: T grading unknown. 
[46] and Kaplan-Meier analysis was performed to determine biochemical survival, with failure defined by the Phoenix definition (PSA nadir $+2 \mathrm{ng} / \mathrm{mL}$ ). The overall 5 -year biochemical survival rate was $85 \%$.

PSA nadir following HIFU has been evaluated and shown to be a robust indicator of treatment failure [46]. In a 6-month study involving 115 patients, failure rates following HIFU were $11 \%$ in patients with a PSA nadir of $0.0-0.2 \mathrm{ng} / \mathrm{ml}$ compared with $46 \%$ in patients with a PSA nadir of $0.21-1 \mathrm{ng} / \mathrm{ml}$, and $48 \%$ in patients with a PSA nadir of $>1.0 \mathrm{ng} / \mathrm{ml}$. In addition, PSA nadir was strongly associated with both preoperative PSA level and residual prostate volume. The utility of PSA nadir in patients with longer follow-up was reported by Ganzer et al. [47]. With a median follow-up of 4.9 (3 - 8.6) years, patients were divided into three PSA nadir subgroups $(\leq 0.2$ $\mathrm{ng} / \mathrm{ml}, 0.21-1 \mathrm{ng} / \mathrm{ml}$ and $>1 \mathrm{ng} / \mathrm{ml})$. Treatment failure was defined by the ASTRO criteria. This study showed that PSA nadir after HIFU was significantly correlated with treatment failure and disease-free survival rate (DFSR). Treatment failure rates during follow-up were $4.5 \%, 30.4 \%$, and $100 \%$, respectively, for the three PSA nadir groups $(\mathrm{P}<0.001)$. The actuarial disease-free survival rates at 5 years were $95 \%, 55 \%$, and $0 \%$, respectively, for the 3 groups $(\mathrm{P}<0.001)$. These findings suggested a long-term improvement in cancer control with the achievement of PSA nadir of $\leq 0.2 \mathrm{ng} / \mathrm{ml}$.

In a series of 120 patients with localized prostate cancer and PSA values of $<10 \mathrm{ng} / \mathrm{ml}$, cancer-free survival rates were examined [6]. The calculated cancer-free 5year survival rate for the overall patient population was $76.9 \%, 85.4 \%$ in highly differentiated tumors (Gleason scores 2-6), and $61.3 \%$ in poorly-differentiated tumors (Gleason scores 7-10). There were no significant differences in survival rates based on prostate volume or the number of positive biopsies. Also, PSA nadir displayed predictive relevance, with actuarial 5-year survival rates of $86 \%$ in patients with a nadir PSA $<0.5 \mathrm{ng} / \mathrm{ml}$.

A European multicenter study reported the short-term results of 402 patients with localized prostate cancer (T1-2/N0-x/M0) treated between 1995 and 1999 [48]. At 1-year follow-up, $87.2 \%$ of control biopsies were negative. When stratified by prognostic risk, the negative biopsy rate was $92.1 \%$ in low risk (Gleason $<7$ ) patients, $86.4 \%$ in medium risk (Gleason 7 ) patients, and $82.1 \%$ in high risk (Gleason $>7$ ) patients. PSA nadir occurred 3 to 4 months after HIFU treatment, and was significantly influenced by the prostate volume in relation to the extent of completeness of the HIFU treatment.

Blana et al. [5] reported the results of 140 patients with baseline PSA $\leq 15 \mathrm{ng} / \mathrm{ml}$ and Gleason score $\leq 7$. TRUS biopsies 6 months following HIFU treatment were negative in $93.4 \%$ of patients. The mean PSA nadir was $0.07 \mathrm{ng} / \mathrm{ml}$, with PSA values remaining stable at a mean of $0.16 \mathrm{ng} / \mathrm{ml}$ during the 22 month mean observation period. The rates of freedom from biochemical relapse at 5- and 7-year follow-ups were $77 \%$ and $69 \%$, respectively, which are comparable to those reported in large studies of standard curative therapies for localized prostate cancer [49-51].

A study with the longest patient follow-up was published in 2010 by Crouzet et al. [52]. The authors reported the results of a multicenter trial consisting of 803 patients followed for a mean of $42 \pm 33$ months. Based on the Phoenix definition, 5- and 7-year biochemical survival was achieved by $83 \%$ and $75 \%$ of low-risk patients, respectively, and by $72 \%$ and $63 \%$ of intermediate-risk patients, respectively. Negative biopsy rates for low- and intermediate-risk patients were $84.9 \%$ and $73.5 \%$, respectively. Also observed was an 8-year overall, metastasis-free, and cancer-specific survival of $89 \%, 97 \%$, and $99 \%$, respectively.

\section{Incidental disease}

Histological examination reveals prostate cancer in up to $8 \%$ of the patients who undergo adenomectomy/holmium-laser enucleation or transurethral resection of the prostate (TURP) because of symptomatic benign prostatic hyperplasia. Consequently, these patients need a therapeutic approach for their prostate cancer [35].

Results have been reported on 65 patients treated with HIFU for incidental prostate cancer. Patients had an average age of 70 years, a median initial PSA of $4.9 \mathrm{ng} / \mathrm{mL}$ and prostate volume of $39 \mathrm{~mL}$, of which an average of 20 $\mathrm{g}(1-95 \mathrm{~g})$ had been resected. Histology showed 5\% (5\% to $50 \%$ ) positive chips and an average Gleason scale of 5 (3 - 9). Patients were treated with single-session full-gland transrectal HIFU. At follow-up, a median PSA nadir of $0.07 \mathrm{ng} / \mathrm{mL}$ was achieved at 1.8 months, including $62 \%$ with PSA $<0.1 \mathrm{ng} / \mathrm{mL}$ and $81 \%$ with PSA $<0.5$ $\mathrm{ng} / \mathrm{mL}$. A median PSA of $0.13 \mathrm{ng} / \mathrm{mL}$, equivalent to a median PSA velocity of $0.01 \mathrm{ng} / \mathrm{mL} / \mathrm{y}$, was found after a median follow-up of 48 months. Intraoperative and postoperative side effects were minimal (Clavien classification: $<15 \%$ I-III). Long-term follow-up showed 45\% secondary obstruction caused by necrotic tissue or bladder neck stenosis. Other long-term side effects included grade I urinary stress incontinence in 11\% (no Grade II or III stress incontinence) and UTI in $14 \%$. There was no cancer-specific mortality [9].

The PSA nadir of $0.07 \mathrm{ng} / \mathrm{mL}$ and the PSA velocity of $0.01 \mathrm{ng} / \mathrm{mL} / \mathrm{y}$ indicated that HIFU can be used as a curative therapy in patients with incidental prostate cancer. These results show that the psychological burden of these patients, who are confronted by having to choose between either the anxiety of living with untreated malignancy with surveillance, or radical surgery or radiation and the risk of significant and long-term side effects, now have the option of cancer control with noninvasive 
HIFU therapy [9].

\subsection{HIFU-Related Morbidity}

The most common side effects of primary HIFU therapy include prolonged voiding dysfunction and retention caused by edema, necrosis or bladder outlet obstruction, as well as erectile dysfunction. Among patients receiving HIFU as primary therapy, Grade I stress incontinence occurs in $4 \%-6 \%$ of patients, Grade II in $0 \%-2 \%$, and secondary infravesical obstruction in $5 \%-10 \%$. Severe incontinence (Grade III) and urethra-rectal fistulae are rare $(<1 \%)$. Urinary tract infections are common $(2 \%$ $48 \%$ ) but the incidence has greatly decreased with the introduction of TURP. Erectile dysfunction occurs at rates of $32 \%-61 \%$. Preservation of erectile function is directly dependent on the position of the primary lesion in relation to the neurovascular bundle. An approach to greater preserve potency involves leaving a 5-mm lateral margin on the contralateral side in men with positive biopsy results confined to one side of the prostate. Although sparing the contralateral side for neurovascular preservation can improve potency, this approach also results in a higher rate of re-treatment [4,44,53-55]. Morbidity with HIFU is summarized in Table 2.

To reduce the time of urinary diversion and postoperative morbidity (sludging, obstruction, infection), studies were undertaken to observe the effects of combining
HIFU with TURP. In 30 patients with localized prostate cancer a one-stage (in the same anesthesia) combination therapy with TURP and HIFU was performed. At 6month follow-up, the mean PIPSS (Post-treatment International Prostate Symptom Score) was 6.7 compared with a pre-treatment score of 7.5 [36]. A study of combination TURP and HIFU treated 96 patients with HIFU monotherapy and 175 with combination therapy. The monotherapy group required a suprapubic catheter for 40 days compared with 7 days in the combination group [2].

Chaussy and Thuroff compared the outcomes of a series of 175 patients treated with HIFU combined with TURP with those of 96 patients previously treated with HIFU alone [2]. No significant differences were found between the two treatment groups in PSA nadir or positive biopsy rate, consistent with subsequent studies finding comparable efficacy between HIFU plus TURP and HIFU alone $[36,43,44]$. However, the lower re-treatment rate in the HIFU/TURP group at $4 \%$ compared with $25 \%$ in the HIFU alone group suggests a benefit of TURP prior to HIFU through the removal of calcifications of the transitional zone that would prevent optimal HIFU treatment. Also found was that the rate of urinary tract infections was significantly reduced in patients undergoing the combined TURP/HIFU procedure compared with HIFU alone ( $11.4 \%$ vs. $47.9 \%, \mathrm{p} \leq 0.001)$.

A study examining the relationship between HIFU

Table 2. Summary of morbidity results following high-intensity focused ultrasound.

\begin{tabular}{|c|c|c|c|c|c|c|c|c|c|}
\hline $\begin{array}{c}\text { Study } \\
\text { (year) [Ref.] }\end{array}$ & Number & INC (\%) & ED (\%) & FIS (\%) & S\&S (\%) & PR (\%) & UTI (\%) & CA (days) & Pain (\%) \\
\hline $\begin{array}{l}\text { Blana et al. } \\
(2004)[45]\end{array}$ & 146 & 5.8 & 57.2 & 0.7 & 11.7 & NR & 4.1 & SP: 12.7 & 1.4 \\
\hline $\begin{array}{l}\text { Thüroff et al. } \\
\text { (2003) [37] }\end{array}$ & 402 & GI 10.6; GII 2.5; GIII 1.5 & 13 & 1.2 & 3.6 & 8.6 & 13.8 & F: $5 \quad$ SP: 34 & NR \\
\hline $\begin{array}{l}\text { Gelet et al. } \\
\text { (2001) [44] }\end{array}$ & 102 & GI 8.8; GII 9.8; GIII 3.9 & 61 & 1 & 17 & 5 & NR & 9.1 & 2 \\
\hline $\begin{array}{l}\text { Chaussy et al. } \\
(2003) \text { no TURP [40] }\end{array}$ & 96 & GI 9.1; GII 4.6; GIII 1.7 & 40 & NR & 27.1 & NR & 47.9 & SP: 45.1 & NR \\
\hline $\begin{array}{l}\text { Chaussy et al. } \\
\text { (2003) TURP [40] }\end{array}$ & 175 & GI 4.6; GII 2.3 & 31.8 & NR & 8 & NR & 11.4 & SP: 13.7 & NR \\
\hline $\begin{array}{l}\text { Ficarra et al. } \\
(2006)[46]\end{array}$ & 30 & 7 & NR & 0 & 10 & 13 & 16 & SP: 12 & NR \\
\hline $\begin{array}{l}\text { Poissonnier et al. } \\
(2007) \text { [47] }\end{array}$ & 227 & GI 9.0; GII 3.0; GIII 1.0 & 39 & 0 & 12 & 9 & 2 & 7 & 3 \\
\hline $\begin{array}{l}\text { Blana et al. } \\
\text { (2008) Multi [48] }\end{array}$ & 140 & GI 5.0; GII 0.7 & 43.2 & 0 & 13.6 & & 7.1 & NR & 5.7 \\
\hline $\begin{array}{l}\text { Blana et al. } \\
\text { (2008) Single [49] }\end{array}$ & 163 & GI 6.1 ; GII 1.8 & 44.7 & 0 & 24.5 & & 7.8 & NR & 3.7 \\
\hline
\end{tabular}

CA: Postoperative catheter duration; ED: Erectile dysfunction; F: Foley catheter; FIS: Fistula; GI: Incontinence grade I, that is loss of urine under heavy exercise requiring 0 - 1 pad/day; GII: Incontinence grade II, that is loss of urine under light exercise requiring $>1$ pad/day; GIII: Incontinence grade III, that is loss of urine under any exercise requiring >2 pads/day; INC: Incontinence; NR: Not reported; PR: Postoperative retention; SP: Suprapubic catheter; S\&S: Stricture and stenosis; TURP: Transurethral resection of the prostate; UTI: Urinary tract infection. 
dose, side effects, and outcome compared a less aggressive treatment strategy involving non-overlapping prostate treatment areas with an overlapping strategy and more aggressive treatment. Dose escalation resulted in a higher cancer-free rate and lower PSA nadir level, but also in a longer duration of urinary retention due to the presence of increased necrotic debris if adjuvant TURP was not performed [56].

\subsection{HIFU Therapy in Locally Advanced, Hormone-Refractory, and Advanced Disease}

In contrast to most published trials of HIFU therapy that report the outcomes in patients with Stage T1-T2 disease or radiation failure, the results of a trial that enrolled 113 patients with Stage T3-T4 disease followed for a median of 4.6 years was recently presented [57]. The median PSA velocity of this cohort was $0.19 \mathrm{ng} / \mathrm{mL} / \mathrm{y}$ and the cancer-specific survival was $96.4 \%$. Another study reported the outcomes of 55 men with PSA progression and local biopsy-proven tumor recurrence during definitive hormonal ablation therapy who received HIFU for hormonal resistant prostate cancer [58]. With a mean follow-up of 21 months, the prostate cancer-specific survival was $87.3 \%$. The results of both studies are impressive and encouraging because this group of patients has a very poor prognosis and a short median survival.

Preliminary results of palliative treatment with HIFU in patients with advanced prostate cancer showed promising findings based on reductions in local morbidity such as rectal compression, infravesical obstruction, hydronephrosis, hematuria, and pelvic pain-syndromes. Unpublished data from several large patient groups $(n>70)$ with Stage T3 and HRPCa with follow-up of 10 years have shown a post-HIFU PSA velocity of $0.19 \mathrm{ng} / \mathrm{ml} /$ year in T3 disease without additional hormone ablation. Local tumor ablation with HIFU has also resulted in a PSA reduction of $80 \%$ in HRPCa cases. There was also evidence of a synergistic effect with hormone ablative therapies that was reflected in the delay of onset of hormone resistance $[10,59]$.

\section{HIFU as Salvage Therapy}

\subsection{Rationale}

HIFU can be used as salvage therapy for locally recurrent disease following almost every curative prostate cancer modality, including external radiation, low-dose rate and high-dose rate brachytherapy cryoablation, primary HIFU, biochemically progressing PSA, and after combined pretreatment including radical prostatectomy. One of the factors accounting for the attractiveness of salvage HIFU is related to the very limited treatment options for men with recurrent disease following curative therapy. Ac- cording to CaPSURE data [37], 63\% of the patients treated with XRT experience disease recurrence. Androgen deprivation therapy was used as salvage therapy in $93.5 \%$ of cases, and definitive local therapy in only $3.9 \%$ (salvage radical prostatectomy $0.9 \%$, and cryoablation $3.0 \%$ ). The appeal of salvage radical prostatectomy and cryoablation following local radiation failure is more theoretical in nature; in practice, their use represents a complex procedure associated with very high morbidity rates and procedural costs [9].

\subsection{Salvage of Radiotherapy Failure}

Murat et al. [60] reported the outcomes of 167 men who underwent salvage HIFU for locally radiorecurrent prostate cancer. The results indicate a $73 \%$ negative biopsy rate and a 5-year overall survival rate of $84 \%$. Biochemical disease-free survival rates were not reported. No rectal complications were observed, but the urinary incontinence rate was $49.5 \%$, similar to rates reported in salvage radical prostatectomy series. Berge et al. [61] reported the early results of a prospective study of salvage HIFU, and observed a biochemical failure rate of $39.1 \%$. Significantly, the urinary incontinence rate was much lower in their cohort than in the Murat et al. study population, with $17.3 \%$ developing either grade II or grade III incontinence. One patient developed a rec- tourethral fistula.

Gelet et al. also reported the results of salvage HIFU in locally recurrent prostate cancer after external-beam radiotherapy [31]. Among the 71 patients, the mean time of recurrence after external beam radiotherapy was 38.5 months (range 6 - 120) and the mean PSA prior to HIFU was $7.7 \mathrm{ng} / \mathrm{ml}$ (range 0.5 - $54 \mathrm{ng} / \mathrm{ml}$ ). With a mean follow-up of 14.8 months (range $6-86$ ), $80 \%$ of patients produced negative biopsies, corresponding to a 30 -month actuarial negative biopsy rate of $73 \%$. The actuarial disease-free rate, based on biopsy and PSA response, was $38 \%$ at 30 months.

Salvage HIFU represents a viable treatment option for men experiencing recurrence after radiation therapy. Although the tissue alteration from radiation therapy results in a higher postoperative morbidity rate than is seen in primary HIFU therapy alone [9], this does not alter the favorable risk-benefit ratio with the use of salvage HIFU treatment relative to the other available options [60].

Very limited experience exists with salvage HIFU following brachytherapy, but it appears that this approach is not associated with a significant increase in complications compared to primary HIFU. It is absolutely necessary to monitor the position of the seeds precisely with MRI before HIFU. There should be no seeds outside the prostate capsule, and especially between rectum and prostate as seeds in these regions would interfere with the 
direct entry path of the ultrasound [1].

\subsection{Salvage of Radical Prostatectomy Failure}

Therapeutic options for local recurrence following radical prostatectomy are limited. HIFU offers a treatment option when local recurrence can be identified through transrectal ultrasound and verified with biopsy. After a small number of patients with post-prostatectomy failure were treated with HIFU, the treated areas showed negative biopsies in $77 \%$ of cases. The PSA nadir averaged $0.2 \mathrm{ng} / \mathrm{ml}$ and $66 \%$ of patients achieved a PSA Nadir < $0.5 \mathrm{ng} / \mathrm{ml}$. During follow-up of 5 years, $91 \%$ of the patients showed no biochemical progression $[59,62]$.

\subsection{Salvage Radical Prostatectomy Following HIFU Failure}

Radical prostatectomy was performed in 7 patients experiencing failure following treatment with HIFU between 1996 and 2000. Prior treatment with HIFU created severe fibrotic adhesions between the rectum and Denovillier's fascia, and although this made salvage radical prostatectomy more technically demanding, it did not result in higher morbidity compared to a standard prostatectomy. The authors attribute these cases of HIFU failure to the incomplete treatment of larger sized prostate glands before the routine use of TURP [1].

\section{Focal and Partial HIFU Therapy}

Over the past 25 years, the average life expectancy of men has increased almost 4 years while the average age of prostate cancer diagnosis has decreased 10 years [63, 64]. Prostate cancer is also detected at a much earlier stage than two decades ago, with the majority of patient candidates for curative whole-prostate therapy. A sizable number of patients with small-volume monofocal tumor are being over-treated with whole-gland approaches that surgically remove or irradiate the entire prostate, and a great need exists for a focal approach to the treatment of small-volume single-lobe prostatic tumor.

The goal of focused HIFU therapy is to provide a partial treatment that is limited to the tumor and a safety margin in patients with noninvasive, monofocal, localized prostate cancer. Such an approach would preserve normal genitourinary function while treating the malignancy with sufficient efficacy $[65,66]$. Two focused treatment approaches with HIFU are currently being evaluated, a precise focal therapy that treats a maximum $25 \%$ of prostate volume without TURP, and a potency-preserving partial therapy that excludes the contralateral lobe/capsule and neurovascular bundle by sparing $5 \mathrm{~mm}$ of tissue on the contralateral lobe and treating up to $90 \%$ of the prostate [21].
A critical issue in focused prostate cancer therapies concerns appropriate patient selection by eliminating those with bilateral tumor. Effective tumor visualization and mapping is essential in achieving this objective. Transperineal 3D mapping biopsies are more accurate than transrectal ultrasound-guided biopsies in excluding patients with clinically significant disease outside the areas to be ablated, and 3D biopsy has been found to increase Gleason scale gradings relative to conventional biopsy [67]. Tumor localization within the prostate of the so-called "index lesion" on which to focus therapy, and post-therapy monitoring is another important concern. The variable sensitivity of MRI [68,69] has prompted the investigation of other functional imaging techniques. Results suggest that vascular information from dynamic contrast-enhanced MRI or diffusion-weighted MRI combined with metabolic data from magnetic resonance spectroscopic imaging may greatly improve the accuracy in defining and staging prostate cancer [70,71]. There are also issues related to how best to monitor patients following treatment [21]. Despite these issues, the results of focused HIFU therapy are highly anticipated.

\section{Prediction of HIFU Treatment Outcome}

The prediction of treatment outcome in patients receiving radical prostatectomy is based on the pathological features of the removed prostate gland such as tumor category, nodal and margin status, and prostatectomy Gleason score. The absence of histological specimens following HIFU necessitates the use of other predictors of treatment outcome. The pretreatment characteristics of disease stage, PSA level and GS at biopsy have been used prognostically in HIFU-treated patients. The results of a series published in 2001 involved 102 patients with T1-T2 disease. At a mean follow-up of 19 months, overall disease-free survival was 66\% [42]. Differences in treatment outcome were observed between initial PSA < $10 \mathrm{ng} / \mathrm{ml}(73 \%$ vs. $50 \% ; \mathrm{p}=0.02)$; Gleason score $<6$ ( $81 \%$ vs. $46 \%$; p < 0.001$)$; and pretreatment sextant biopsy revealing one to four positive samples ( $68 \%$ vs. $40 \%$; $\mathrm{p}=0.01$ ). Poissonier et al. studied the outcomes of 227 patients, and reported an actuarial 5-year DFSR of $66 \%$ [44]. DFSR varied when patients were stratified according to pre-treatment PSA level: The DFSR was $90 \%$ with PSA $<4 \mathrm{ng} / \mathrm{ml}$ versus $57 \%$ and $61 \%$ with pretreatment PSA of $4.1-10 \mathrm{ng} / \mathrm{ml}$ and $10.1-15 \mathrm{ng} / \mathrm{ml}$, respectively.

Prostate-specific antigen nadir has been evaluated as a predictor of clinical failure following HIFU [72]. In a 6-month study involving 115 patients, failure rates following HIFU were $11 \%$ (four out of 36) in patients with a PSA nadir of $0.0-0.2 \mathrm{ng} / \mathrm{ml}$, compared with $46 \%$ (17 out of 37) in patients with a PSA nadir of $0.21-1 \mathrm{ng} / \mathrm{ml}$, and $48 \%$ (20 out of 42$)$ in patients with a PSA nadir > 
$1.0 \mathrm{ng} / \mathrm{ml}$. In addition, PSA nadir was strongly associated with both preoperative PSA level and residual prostate volume. The predictive utility of PSA nadir in patients with longer follow-up was reported by Ganzer et al. [47]. The median follow-up in their study was 4.9 (range: 3 8.6) years. Patients were divided into three PSA nadir subgroups $(\leq 0.2,0.21-1$, and $\geq 1 \mathrm{ng} / \mathrm{ml})$ and treatment failure was defined according to ASTRO criteria. PostHIFU PSA nadir was shown to be significantly associated with treatment failure and DFSR; failure rates during follow-up were $4.5 \%, 30.4 \%$ and $100 \%$ for patients with PSA nadirs of $\leq 0.2 \mathrm{ng} / \mathrm{ml}, 0.21$ to $1 \mathrm{ng} / \mathrm{ml}$, and $\geq 1$ $\mathrm{ng} / \mathrm{ml}$, respectively $(\mathrm{p} \leq 0.001)$. The actuarial DFSRs at 5 years were $95 \%, 55 \%$ and $0 \%$, respectively, for the three PSA nadir groups $(p \leq 0.001)$. These findings suggest that HIFU outcome is improved if a PSA nadir of less than $0.2 \mathrm{ng} / \mathrm{ml}$ is achieved.

\section{Immunologic Response with HIFU Therapy}

Progress has been made in developing an effective immune strategy for treating prostate cancer. A number of immunotherapy regimens are being studied including immunomodulatory cytokines/effectors, peptide and cellular immunization, viral vaccines, dendritic cell vaccines, and antibody therapies. Immunomodulatory agents, such as granulocyte-macrophage colony-stimulating factor (GM-CSF), Flt3 ligand, and IL-2, have been used to stimulate the immune system to generate an antitumor response against prostate cancer. However, the encouraging early preclinical results have not been extended into the clinical setting.

Several recent studies have examined the potential of HIFU to initiate an immune response. Wu et al. studied the effect of HIFU on systemic antitumor immunity, particularly $\mathrm{T}$ lymphocyte-mediated immunity in cancer patients [73]. HIFU was used to treat 16 patients with solid malignancies, including osteosarcoma, hepatocellular carcinoma and renal cell carcinoma. HIFU led to a significant increase in the population of CD4+ lymphocytes and the ratio of $\mathrm{CD} 4+/ \mathrm{CD} 8+$ in circulation. The authors concluded that HIFU could enhance a systemic anti-tumor cellular immunity in addition to local tumor destruction in patients with solid malignancies.

The same research group investigated whether tumor antigens expressed on breast cancer cells could be preserved after HIFU treatment [74]. Primary lesions in 23 patients with biopsy-proven breast cancer were treated with HIFU, then submitted to modify radical mastectomy. Breast cancer specimens were then stained for a variety of cellular molecules, including tumor antigens and heatshock protein 70 (HSP-70). A number of tumor antigens were identified that could provide a potential antigen source to stimulate antitumor immune response.

It has been suggested that endogenous signals from HIFU-damaged tumor cells may trigger the activation of dendritic cells, playing a critical role in a HIFU-elicited antitumor immune response [75]. A mouse model bearing MC-38 colon adenocarcinoma tumors was treated with thermal and mechanical HIFU exposure settings. Results showed that HIFU elicited a systemic anti-tumor immune response that was related closely to dendritic cell activation, and that dendritic cell activation was more pronounced when tumor cells were mechanically lysed by HIFU.

HIFU ablation of human breast cancer was found to result in a significant increase in the numbers of tumorinfiltrating CD3, CD4, CD8, CD4/CD8, B lymphocytes, and NK cells, and in a substantially increased tumorinfiltrating lymphocyte invasion along the margins of ablated regions in all HIFU-treated neoplasms. Also, the number of $\operatorname{FasL}(+)$, granzyme $(+)$, and perforin( $(+)$ tmorinfiltrating lymphocytes was significantly greater in the HIFU group than in the control group [76].

\section{Future Directions of HIFU for Prostate Cancer}

The efficacy in cancer control of HIFU and other focal therapies will depend less on the development of therapeutic tools than on diagnostic technologies that can more accurately image and localize tumor lesions and foci. When this goal is reached, HIFU will be an ideal therapeutic tool for focal prostate cancer treatment. To achieve this goal, several advancements in imaging technologies are being investigated for use with HIFU, including MRI, ultrasound and Doppler for lesion targeting, and MRI and ultrasound for use with thermometry.

With over 10 years of clinical use in over 30,000 patients, prostate cancer is the leading application of HIFU, followed by the treatment of uterus fibromas and myomas. Other applications for HIFU being investigated include breast cancer, brain cancer, thyroid cancer, thrombolysis, the use of HIFU as a drug delivery device, and also for the "sealing" of blood vessels. The clinical future of HIFU will focus primarily on the treatment of soft tissue pathologies directly below the body surface with targeting volumes less than $20 \mathrm{cc}$ (prostate, breast and thyroid) due to the limited penetration depth of HIFU. Drug delivery involving the accumulation of drugs in defined organ regions or genetic manipulation is anticipated to be a promising area of future HIFU research, and HIFU-provoked induction of immune response as a supportive therapy is under investigation [1].

\section{Conclusions}

Prostate cancer is now diagnosed at an earlier disease 
stage in younger patients with a longer life expectancy than it was 20 years ago before widespread PSA screening. As a result, the window for curative therapy has been extended, and with patients living longer after definitive therapy, a greater emphasis is now placed on treatment-related morbidity and its impact on patient quality of life. Local recurrence occurs in $10 \%-50 \%$ of patients regardless of curative approach, and the treatment of prostate cancer has evolved from a singular treatment to a multimodal, sequential approach that greatly accommodates the use of minimally invasive therapies such as HIFU. Decreasing resources for medical care are adding to the urgency for the development and clinical use of cost-effective non-invasive therapies.

Since 2000, prostate cancer therapy with the Ab- latherm ${ }^{\circledR}$ HIFU device has progressed from an experimental therapy to a therapy under long-term investigation for primary treatment of local prostate cancer and salvage therapy after radiation failure. Preliminary data suggest that HIFU may also be effective in the treatment of focal and incidental prostate cancer, as adjuvant therapy in T3/T4 disease, and in nonmetastatic hormoneresistant prostate cancer. This range of indications across the spectrum of prostate cancer appears to be a unique attribute of HIFU [19,31]. Additionally, HIFU can be repeated in cases of local recurrence, which is not an option with other treatment modalities for localized prostate cancer such as cryosurgery and brachytherapy.

The use of HIFU should not be viewed as a substitute or replacement for classical therapy, but instead as a therapeutic first choice in monofocal well-differentiated disease. The initial use of HIFU can help postpone the need for invasive therapies associated with greater morbidity such as surgery or radiation, allowing the patient a longer period without the risk of living with treatmentrelated genitourinary side effects [77].

Transrectal HIFU should be given serious consideration as a curative therapy in localized disease as well as a palliative adjuvant therapy in all other tumor stages. Ongoing improvements in imaging technologies are expected to further enhance the efficacy of HIFU.

\section{Acknowledgements}

The authors thank Regina Nanieva and Dr. Tina Chaussy for their invaluable help.

\section{REFERENCES}

[1] C. G. Chaussy, "Ultrasonidos De Alta Intensidad Focalizados (HIFU) Para el Tratamiento Local del Cancer de Prostata: Papel Actual," Archivos Españoles de Urología, Vol. 64, No. 6, 2011, pp. 493-506.

[2] C. H. Chaussy and S. Thuroff, "The Status of High-Intensity Focused Ultrasound in the Treatment of Localized
Prostate Cancer and the Impact of a Combined Resection," Current Urology Reports, Vol. 4, No. 3, 2003, pp. 248-252. doi:10.1007/s11934-003-0077-0

[3] C. Chaussy and S. Thuroff, "Results and Side Effects of High Intensity Focused Ultrasound in Localized Prostate Cancer," Journal of Endourology, Vol. 15, No. 4, 2001, pp. 437-440, 447-448. doi:10.1089/089277901300189501

[4] Ch. Chaussy and S. Thuroff, "The Use of High-Intensity Focused Ultrasound in Prostate Cancer," In: O Ukimura and I. S. Gill, Eds., Contemporary Interventional Ultrasonography in Urology, Springer, London, 2009, pp. $63-$ 74. doi:10.1007/978-1-84800-217-3 7

[5] A. Blana, F. J. Murat, B. Walter, S. Thuroff, W. F. Wieland, C. Chaussy and A. Gelet, "First Analysis of the Long-Term Results with Transrectal HIFU in Patients with Localised Prostate Cancer," European Urology, Vol. 53, No. 6, 2008, pp. 1194-1201.

doi:10.1016/j.eururo.2007.10.062

[6] L. Poissonnier, A. Gelet, J. Y. Chapelon, R. Bouvier, O. Rouviere, C. Pangaud, D. Lyonnet and J. M. Dubernard, "Results of Transrectal Focused Ultrasound for the Treatment of Localized Prostate Cancer (120 Patients with PSA < or $+10 \mathrm{ng} / \mathrm{ml})$," Progres en Urologie, Vol. 13, 2003, pp. 60-72.

[7] J. G. Lynn and T. J. Putman, "Histological and Cerebral Lesions Produced by Focused Ultrasound," American Journal of Pathology, Vol. 20, No. 3, 1944, pp. 637-649.

[8] G. ter Haar, "Intervention and Therapy," Ultrasound in Medicine \& Biology, Vol. 23, Suppl. 1, 2000, pp. S51S54. doi:10.1016/S0301-5629(00)00164-2

[9] C. G. Chaussy and S. F. Thüroff, "Robotic High-Intensity Focused Ultrasound for Prostate Cancer: What Have We Learned in 15 Years of Clinical Use?" Current Urology Reports, Vol. 12, No. 3, 2011, pp. 180-187. doi:10.1007/s11934-011-0184-2

[10] C. Chaussy and S. Thüroff, "High-Intensity Focused U1trasound in the Management of Prostate Cancer," Expert Review of Medical Devices, Vol. 7, No. 2, 2010, pp. 209217. doi:10.1586/erd.09.66

[11] J. Y. Chapelon, J. Margonari, Y. Theillère, F. Gorry, F. Vernier, E. Blanc and A. Gelet, "Effects of High-Energy Focused Ultrasound on Kidney Tissue in the Rat and the Dog," European Urology, Vol. 22, No. 2, 1992, pp. 147152.

[12] T. Uchida, N. T. Sanghvi, T. A. Gardner, M. O. Koch, D. Ishii, S. Minei, T. Satoh, T. Hyodo, A. Irie and S. Baba, "Transrectal High-Intensity Focused Ultrasound for Treatment of Patients with Stage T1b-2n0m0 Localized Prostate Cancer: A Preliminary Report," Urology, Vol. 59, No. 3, 2002, pp. 394-398; Discussion pp. 398-399. doi:10.1016/S0090-4295(01)01624-7

[13] J. Y. Chapelon, D. Cathignol, C. Cain, E. Ebbini, J. U. Kluiwstra, O. A. Sapozhnikov, G. Fleury, R. Berriet, L. Chupin and J. L. Guey, "New Piezoelectric Transducers for Therapeutic Ultrasound," Ultrasound in Medicine \& Biology, Vol. 26, No. 1, 2000, pp. 153-159. doi:10.1016/S0301-5629(99)00120-9

[14] L. Curiel, F. Chavrier, R. Souchon, A. Birer and J. Y. 
Chapelon, "1.5-D High Intensity Focused Ultrasound Array for Non-Invasive Prostate Cancer Surgery," IEEE Transactions on Ultrasonics, Ferroelectrics, and Frequency Control, Vol. 49, No. 2, 2002, pp. 231-242. doi: $10.1109 / 58.985707$

[15] J. S. Tan, L. A. Frizzell, N. T. Sanghvi, R. Seip, J. S. Wu and J. T. Kouzmanoff, "Design of Focused Ultrasound Phased Arrays for Prostate Treatment," IEEE Ultrasonics Symposium, Vol. 2, 2000, pp. 1247-1251.

[16] G. O. Oosterhof, E. B. Cornel, G. A. Smits, F. M. Debruyne and J. A. Schalken, "Influence of High Intensity Focused Ultrasound on the Development of Metastases," European Urology, Vol. 32, No. 1, 1997, pp. 91-95.

[17] R. S. Foster, R. Bihrle, N. Sanghvi, F. Fry, K. Kopecky, J. Regan, J. Eble, C. Hennige, L. V. Hennige and J. P. Donohue, "Production of Prostatic Lesions in Canines Using Transrectally Administered High Intensity Focused Ultrasound," European Urology, Vol. 23, No. 2, 1993, pp. 330-336.

[18] A. Gelet, J. Y. Chapelon, J. Margonari, Y. Theillere, F. Gorry, D. Cathignol and E. Blanc, "Prostatic Tissue Destruction by High-Intensity Focused Ultrasound: Experimentation on Canine Prostate," Journal of Endourology, Vol. 7, No. 3, 1993, pp. 249-253. doi:10.1089/end.1993.7.249

[19] C. Chaussy, S. Thüroff, X. Rebillard and A. Gelet, "Technology Insight: High-Intensity Focused Ultrasound for Urologic Cancers," Nature Clinical Practice Urology, Vol. 2, No. 4, 2005, pp. 191-198. doi:10.1038/ncpuro0150

[20] X. Rebillard, J. L. Davin and M. Soulié, "Comité de Cancérologie de l'Association Française d'Urologie. Treatment by HIFU of Prostate Cancer: Survey of Literature and Treatment Indications," Progrès en Urologie, Vol. 13, No. 6, 2003, pp. 1428-1456.

[21] C. G. Chaussy and S. Thüroff, "Robot-Assisted HighIntensity Focused Ultrasound in Focal Therapy of Prostate Cancer," Journal of Endourology, Vol. 24, No. 5, 2010, pp. 843-847. doi:10.1089/end.2009.0439

[22] Misonix/US HIFU, "HIFU with the Sonablate 5000," 2011. http://www.ushifu.com/

[23] H. P. Beerlage, G. J. van Leenders, G. O. Oosterhof, J. A. Witjes, E. T. Ruijter, C. A. van de Kaa, F. M. Debruyne and J. J. de la Rosette, "High-Intensity Focused Ultrasound (HIFU) Followed after One to Two Weeks by Radical Retropubic Prostatectomy: Results of A Prospective Study," Prostate, Vol. 39, No. 1, 1999, pp. 41-46.

[24] O. Rouviere, D. Lyonnet, A. Raudrant, C. Colin-Pangaud, J. Y. Chapelon, R. Bouvier, J. M. Dubernard and A. Gelet, "MRI Appearance of Prostate Following Transrectal HIFU Ablation of Localized Cancer," European Urology, Vol. 40, No. 3, 2001, pp. 265-274. doi:10.1159/000049786

[25] K. Hynynen, W. R. Freund, H. E. Cline, A. H. Chung, R. D. Watkins, J. P. Vetro and F. A. Jolesz, "A Clinical, Noninvasive, MR Imaging-Monitored Ultrasound Surgery Method," Radiographics, Vol. 16, No. 1, 1996, pp. 185-195.

[26] C. Damianou, M. Pavlou, O. Velev, K. Kyriakou and M.
Trimikliniotis, "High Intensity Focused Ultrasound Ablation of Kidney Guided by MRI," Ultrasound in Medicine \& Biology, Vol. 30, No. 3, 2004, pp. 397-404. doi:10.1016/j.ultrasmedbio.2003.10.018

[27] T. Wu, J. P. Felmlee, J. F. Greenleaf, S. J. Riederer and R. L. Ehman, "Assessment of Thermal Tissue Ablation with MR Elastography," Magnetic Resonance in Medicine, Vol. 45, No. 1, 2001, pp. 80-87. doi:10.1002/1522-2594(200101)45:1<80::AID-MRM101 2>3.0.CO;2-Y

[28] S. Vaezy, X. Shi, R. W. Martin, E. Chi, P. I. Nelson, M. R. Bailey and L. A. Crum, "Real-Time Visualization of High-Intensity Focused Ultrasound Treatment Using U1trasound Imaging," Ultrasound in Medicine \& Biology, Vol. 27, No. 1, 2001, pp. 33-42. doi:10.1016/S0301-5629(00)00279-9

[29] J. P. Sedelaar, R. G. Aarnink, G. J. van Leenders, H. P. Beerlage, F. M. Debruyne, H. Wijkstra and J. J. de La Rosette, "The Application of Three-Dimensional Contrast-Enhanced Ultrasound to Measure Volume of Affected Tissue after HIFU Treatment for Localized Prostate Cancer," European Urology, Vol. 37, No. 5, 2000, pp. 559-568. doi: $10.1159 / 000020193$

[30] J. Lu, H. Ying, Z. Sun, M. Motamedi, B. Bell and L. C. Sheppard, "In Vitro Measurement of Speed of Sound during Coagulate Tissue Heating," Ultrasonics Symposium Proceedings, Vol. 2, 1996, pp. 1299-1302.

[31] A. Gelet, J. Y. Chapelon, L. Poissonnier, R. Bouvier, O. Rouvière, L. Curiel, M. Janier and G. Vallancien, "Local Recurrence of Prostate Cancer after External Beam Radiotherapy: Early Experience of Salvage Therapy Using High-Intensity Focused Ultrasonography," Urology, Vol. 63, No. 4, 2004, pp. 625-629.

[32] C. Chaussy and S. Thueroff, "Complete Remission in Metastatic Prostate Cancer after Combined Local and Systemic Therapy," Urology, Vol. 68, 2006, pp. 197-198. doi:10.1016/j.urology.2006.08.631

[33] V. Ficarra, S. Z. Antoniolli, G. Novara, A. Parisi, S. Fracalanza, G. Martignoni and W. Artibani, "Short-Term Outcome after High-Intensity Focused Ultrasound in the Treatment of Patients with High-Risk Prostate Cancer," BJU International, Vol. 98, No. 6, 2006, pp. 1193-1198. doi:10.1111/j.1464-410X.2006.06561.X

[34] ASTRO, "Consensus Statement: Guidelines for PSA Following Radiation Therapy," International Journal of Radiation Oncology, Biology, Physics, Vol. 37, No. 5, 1997, pp. 1035-1041.

[35] C. G. Chaussy and S. Thueroff, "Transrectal High-Intensity Focused Ultrasound for Local Treatment of Prostate Cancer," Urologe A, Vol. 48, No. 7, 2009, pp. 710-718.

[36] G. Vallancien, D. Prapotnich, X. Cathelineau, H. Baumert and F. Rozet, "Transrectal Focused Ultrasound Combined with Transurethral Resection of the Prostate for the Treatment of Localized Prostate Cancer: Feasibility Study," Journal of Urology, Vol. 171, No. 6, 2004, pp. 2265-2267.

[37] P. K. Agarwal, N. Sadetsky, B. R. Konety, M. I. Resnick and P. R. Carroll, "Cancer of the Prostate Strategic Urological Research Endeavor (CaPSURE). Treatment Failure after Primary and Salvage Therapy for Prostate Can- 
cer: Likelihood, Patterns of Care, and Outcomes," Cancer, Vol. 112, No. 2, 2008, pp. 307-314.

doi:10.1002/cncr.23161

[38] A. Gelet, J. Y. Chapelon, R. Bouvier, R. Souchon, C. Pangaud, A. F. Abdelrahim, D. Cathignol and J. M. Dubernard, "Treatment of Prostate Cancer with Transrectal Focused Ultrasound: Early Clinical Experience," European Urology, Vol. 29, No. 2, 1996, pp. 174-183.

[39] A. Gelet, J. Y. Chapelon, R. Bouvier, C. Pangaud and Y. Lasne, "Local Control of Prostate Cancer by Transrectal High Intensity Focused Ultrasound Therapy: Preliminary Results," Journal of Urology, Vol. 161, No. 1, 1999, pp. 156-162. doi:10.1016/S0022-5347(01)62087-1

[40] A. Gelet, J. Y. Chapelon, R. Bouvier, O. Rouvière, Y. Lasne, D. Lyonnet and J M. Dubernard, "Transrectal HighIntensity Focused Ultrasound: Minimally Invasive Therapy of Localized Prostate Cancer," Journal of Endourology, Vol. 14, No. 6, 2000, pp. 519-528. doi:10.1089/end.2000.14.519

[41] P. Richaud, J. L. Moreau, P. Beuzeboc, X. Rébillard, A. Villers, M. Peyromaure, F. Cornud, M. Soulié and J. L. Davin, "Follow-Up of Prostate Cancer. Guidelines of the French Urological Association Oncology Committee," Progres en Urologie, Vol. 15, 2005, pp. 586-592.

[42] A. Gelet, J. Y. Chapelon, R. Bouvier, O. Rouvière, D. Lyonnet and J. M. Dubernard, "Transrectal High Intensity Focused Ultrasound for the Treatment of Localized Prostate Cancer: Factors Influencing the Outcome," European Urology, Vol. 40, No. 2, 2001, pp. 124-129. doi:10.1159/000049761

[43] A. Blana, S. Rogenhofer, R. Ganzer, J. C. Lunz, M. Schostak, W. F. Wieland and B. Walter, "Eight Years' Experience with High-Intensity Focused Ultrasonography for Treatment of Localized Prostate Cancer," Urology, Vol. 72, No. 6, 2008, pp. 1329-1333. doi:10.1016/j.urology.2008.06.062

[44] L. Poissonnier, J. Y. Chapelon, O. Rouvière, L. Curiel, R. Bouvier, X. Martin, J. M. Dubernard and A. Gelet, "Control of Prostate Cancer by Transrectal HIFU in $227 \mathrm{~Pa}-$ tients," European Urology, Vol. 51, No. 2, 2007, pp. 381387. doi:10.1016/j.eururo.2006.04.012

[45] A. Blana, S. C. W. Brown, C. Chaussy, G. N. Conti, J. A. Eastham, R. Ganzer, F. J. Murat, X. Rebillard, J. C. Rewcastle, C. N. Robertson, S. Thueroff, J. F. Ward and A. Gelet, "Primary Prostate HIFU without Pretreatment Hormone Therapy: Biochemical Survival of 763 Patients Tracked with the @-Registry," European Urology Supplements, Vol. 8, No. 4, 2009, p. 333. doi:10.1016/S1569-9056(09)60838-1

[46] A. V. D'Amico, J. Moul, P. R. Carroll, L. Sun, D. Lubeck and M. H. Chen, "Cancer-Specific Mortality after Surgery or Radiation for Patients with Clinically Localized Prostate Cancer Managed During the Prostate Specific Antigen Era," Journal of Clinical Oncology, Vol. 21 No. 11, 2003, pp. 2163-2172. doi:10.1200/JCO.2003.01.075

[47] R. Ganzer, S. Rogenhofer, B. Walter, J. C. Lunz, M. Schostak, W. F. Wieland and A. Blana, "PSA Nadir Is a Significant Predictor of Treatment Failure after High-Intensity Focused Ultrasound (HIFU) Treatment of Local- ized Prostate Cancer," European Urology, Vol. 53, No. 3, 2008, pp. 547-553. doi:10.1016/j.eururo.2007.07.010

[48] S. Thüroff, C. Chaussy, G. Vallancien, W. Wieland, H. J. Kiel, A. Le Duc, F. Desgrandchamps, J. J. De La Rosette and A. Gelet, "High-Intensity Focused Ultrasound and Localized Prostate Cancer: Efficacy Results from the European Multicentric Study," Journal of Endourology, Vol. 17, No. 8, 2003, pp. 673-677. doi:10.1089/089277903322518699

[49] P. A. Kupelian, M. Elshaikh, C. A. Reddy, C. Zippe and E. A. Klein, "Comparison of the Efficacy of Local Therapies for Localized Prostate Cancer in the Prostate-Specific Antigen Era: A Large Single Institution Experience with Radical Prostatectomy and External-Beam Radiotherapy," Journal of Clinical Oncology, Vol. 20, No. 16, 2002, pp. 3376-3385. doi:10.1200/JCO.2002.01.150

[50] D. A. Kuban, M. Elshaikh, C. A. Reddy, C. Zippe and E. A. Klein, "Long-Term Multi-Institutional Analysis of Stage T1-T2 Prostate Cancer Treated with Radiotherapy in the PSA Era," International Journal of Radiation Oncology, Biology, Physics, Vol. 57, No. 4, 2003, pp. $915-$ 928. doi:10.1016/S0360-3016(03)00632-1

[51] L. Potters, E. A. Klein, M. W. Kattan, C. A. Reddy, J. P. Ciezki, A. M. Reuther and P. A. Kupelian, "Monotherapy for Stage T1-T2 Prostate Cancer: Radical Prostatectomy, External Beam Radiotherapy, or Permanent Seed Implantation," Radiotherapy and Oncology, Vol. 71, No. 1, 2004, pp. 29-33. doi:10.1016/j.radonc.2003.12.011

[52] S. Crouzet, X. Rebillard, D. Chevallier, P. Rischmann, G. Pasticier, G. Garcia, O. Rouviere, J. Y. Chapelon and A. Gelet, "Multicentric Oncologic Outcomes of High-Intensity Focused Ultrasound for Localized Prostate Cancer in 803 Patients," European Urology, Vol. 58, No. 4, 2010, pp. 559-566. doi:10.1016/j.eururo.2010.06.037

[53] C. G. Chaussy and S. Thüroff, "High-Intensive Focused Ultrasound in Localized Prostate Cancer," Journal of Endourology, Vol. 14, No. 3, 2000, pp. 293-299. doi:10.1089/end.2000.14.293

[54] S. Thüroff and C. G. Chaussy, "High-Intensity Focused Ultrasound: Complications and Adverse Events," Molecular Urology, Vol. 4, No. 3, 2000, pp. 183-187.

[55] S. Thüroff, "High-Intensity Focused Ultrasound for Prostate Cancer," In: L.-M. Su and Stephen C. Young, Eds., Early Diagnosis and Treatment of Cancer: Prostate Cancer, Saunders Elsevier, Missouri, 2008, pp. 177-192.

[56] S. Thüroff, C. Chaussy and A. Gelet, "Focused Ultrasound (HIFU) in the Treatment of Prostate Cancer. Energy/Efficacy Correlation. WCE Congress, 2001," Journal of Endourology, Vol. 15, Suppl. 1, 2001, p. S32 (Abstract A3-P10).

[57] C. G. Chaussy and S. F. Thueroff, "HIFU Treatment of Locally Advanced Prostate Cancer," Journal of En- dourology, Vol. 24, Suppl. 1, 2010, p. PS12-2.

[58] C. Chaussy, S. Thuroff and R. Nanieva, "Hormone Resistant Prostate Cancer Treated by Robotic High Intensive Ultrasound," Journal of Urology, Vol. 183, 2010, Article ID: e262.

[59] C. Chaussy, S. Thüroff and T. Bergsdorf, "Local Recur- 
rence of Prostate Cancer after Curative Therapy. HIFU (Ablatherm) as a Treatment Option," Urologe A, Vol 45, No. 10, 2006, pp. 1271-1275. doi:10.1007/s00120-006-1214-4

[60] F. J. Murat, L. Poissonnier, M. Rabilloud, A. Belot, R. Bouvier, O. Rouviere, J. Y. Chapelon and A. Gelet, "MidTerm Results Demonstrate Salvage High-Intensity Focused Ultrasound (HIFU) as an Effective and Acceptably Morbid Salvage Treatment Option for Locally Radiorecurrent Prostate Cancer," European Urology, Vol. 55, No. 3, 2009, pp. 640-647. doi:10.1016/j.eururo.2008.04.091

[61] V. Berge, E. Baco and S. J. Karlsen, "A Prospective Study of Salvage High Intensity Focused Ultrasound for Locally Radiorecurrent Prostate Cancer: Early Results," Scandinavian Journal of Urology, Vol. 44, No. 4, 2010, pp. 223-227.

[62] M. Hayashi, S. Shinmei and K. Asano, "Transrectal HighIntensity Focused Ultrasound for Treatment for Patients with Biochemical Failure after Radical Prostatectomy," International Journal of Urology, Vol. 14, No. 11, 2008, pp. 1048-1050.

[63] M. Marberger, "Prostate Cancer 2008 Challenges in Diagnostic and Management," European Urology, Vol. 8, Suppl. 3, 2009, pp. 1989-1996.

[64] P. J. van Leeuwen, D. Connolly, T. L. Tammela, A. Auvinen, R. Kranse, M. J. Roobol, F. H. Schroder and A. Gavin, "Balancing the Harms and Benefits of Early Detection of Prostate Cancer," Cancer, Vol. 116, 2010, No. 20, pp. 4857-4865.

[65] L. Klotz, "Active Surveillance for Prostate Cancer: For Whom?" Journal of Clinical Oncology, Vol. 23, No. 32, 2005, pp. 8165- 8169. doi:10.1200/JCO.2005.03.3134

[66] S. Roemeling, M. J. Roobol, M. W. Kattan, T. H. van der Kwast, E. W. Steyerberg and F. H. Schröder, "Nomogram Use for the Prediction of Indolent Prostate Cancer: Impact on Screen-Detected Populations," Cancer, Vol. 110, No. 10, 2007, pp. 2218-2221.

[67] G. Onik and W. Barzell, "Transperineal. 3D Mapping Biopsy of the Prostate: An Essential Tool in Selecting Patients for Focal Prostate Cancer Therapy," Urologic Oncology, Vol. 26, No. 5, 2008, pp. 506-510. doi:10.1016/j.urolonc.2008.03.005

[68] O. Rouvière, R. Souchon, R. Salomir, A. Gelet, J. Y. Chapelon and D. Lyonnet, "Transrectal High-Intensity Focused Ultrasound Ablation of Prostate Cancer: Effective Treatment Requiring Accurate Imaging," European Journal of Radiology, Vol. 63, No. 3, 2007, pp. 317-327. doi:10.1016/j.ejrad.2007.06.026
[69] A. P. Kirkham, M. Emberton and C. Allen, "How Good Is MRI at Detecting and Characterising Cancer within the Prostate?" European Urology, Vol. 50, No. 6, 2006, pp. 1163-1174.

[70] J. K. Kim, S. S. Hong, Y. J. Choi, S. H. Park, H. Ahn, C. S. Kim and K. S. Cho, "Wash-In Rate on the Basis of Dynamic Contrast-Enhanced MRI: Usefulness for Prostate Cancer Detection and Localization," Journal of Magnetic Resonance Imaging, Vol. 22, No. 5, 2005, pp. 639646. doi:10.1002/jmri.20431

[71] M. A. Haider, T. H. van der Kwast, J. Tanguay, A. J. Evans, A. T. Hashmi, G. Lockwood and J. Trachtenberg, "Combined T2-Weighted and Diffusion-Weighted MRI for Localization of Prostate Cancer," American Journal of Roentgenology, Vol. 189, No. 2, 2007, pp. 323-328. doi:10.2214/AJR.07.2211

[72] T. Uchida, R. O. Illing, P. J. Cathcart and M. Emberton, "To What Extent does the Prostate-Specific Antigen Nadir Predict Subsequent Treatment Failure after Transrectal High-Intensity Focused Ultrasound Therapy for Presumed Localized Adenocarcinoma of the Prostate," BJU International, Vol. 98, No. 3, 2006, pp. 537-539.

[73] F. Wu, Z. B. Wang, P. Lu, Z. L. Xu, W. Z. Chen, H. Zhu and C. B. Jin, "Activated Anti-Tumor Immunity in Cancer Patients after High Intensity Focused Ultrasound Ablation," Ultrasound in Medicine and Biology, Vol. 30, No. 9, 2004, pp. 1217-1222. doi:10.1016/j.ultrasmedbio.2004.08.003

[74] F. Wu, Z. B. Wang, Y. D. Cao, Q. Zhou, Y. Zhang, Z. L. $\mathrm{Xu}$ and X. Q. Zhu, "Expression of Tumor Antigens and Heat-Shock Protein 70 in Breast Cancer Cells after High Intensity Focused Ultrasound Ablation," Annals of Surgical Oncology, Vol. 14, No. 3, 2007, pp. 1237-1242. doi:10.1245/s10434-006-9275-6

[75] Z. Hu, X. Y. Yang, Y. Liu, G. N. Sankin, E. C. Pua, M. A. Morse, H. K. Lyerly, T. M. Clay and P. Zhong, "Investigation of HIFU-Induced Antitumor Immunity in a Murine Tumor Model," Journal of Translational Medicine, Vol. 5, 2007, p. 34.

[76] P. Lu, X. Q. Zhu, Z. L. Xu, Q. Zhou, J. Zhang and F. Wu, "Increased Infiltration of Activated Tumor Infiltrating Lymphocytes after High Intensity Focused Ultrasound Ablation of Human Breast Cancer," Surgery, Vol. 145, No. 3, 2009, pp. 286-293. doi:10.1016/j.surg.2008.10.010

[77] H. M. Lee, J. H. Hong and H. Y. Choi, "High-Intensity Focused Ultrasound Therapy for Clinically Localized Prostate Cancer," Prostate Cancer and Prostatic Diseases, Vol. 9, No. 4, 2006, pp. 439-443. doi:10.1038/sj.pcan.4500901 